\title{
TESTE REVERSO PARA ANTICORPOS IgM NA TOXOPLASMOSE, COM HEMÁCIAS SENSIBILIZADAS POR ANTÍGENOS DE TOXOPLASMA GONDII
}

\author{
Nancy Navarrete', Mário E. Camargo ${ }^{2}$ e Gastão de Almeida ${ }^{2}$
}

\begin{abstract}
Descreve-se um teste para anticorpos IgM-antitoxoplasma baseado na técnica de captura de IgM do soro por anticorpos anti-IgM adsorvidos a placas plásticas. Para evidenciação dos anticorpos antitoxoplasma nessa fração, utiliza-se uma suspensão de hemácias humanas, formolizadas e sensibilizadas por antigenos de Toxoplasma gondii. Nos testes positivos estas aparecem como uma camada contínua, enquanto que nos testes negativos depositam-se ao fundo das cavidades das placas. A leitura dos testes é muito mais evidente do que na técnica anteriormente proposta por Desmonts e cols, 1981, que utiliza suspensões de toxoplasmas. A suspensão de hemácias sensibilizadas pode ser preparada por simples diluição do reagente para o teste de hemaglutinação para a toxoplasmose.
\end{abstract}

Palavras-chaves: Toxoplasmose. Sorologia. IgM. Teste reverso.

A demonstração de anticorpos séricos antitoxoplasma de classe $\mathbf{M}$ de imunoglobulinas é de grande valor diagnóstico, uma vez que esses anticorpos constituem indicadores de infecção recentemente adquirida do adulto, ou de infecção congênita do recém-nascido.

As técnicas com anticorpos marcados proporcionam testes para essa demonstração, por meio de reações utilizando conjugados fluorescentes 313 ou enzimáticos ${ }^{514}$ de anticorpos anti-IgM. Porém, nesses testes podem ocorrer resultados falsos, tanto positivos como negativos. Assim, a presença de anticorpos antinúcleo ${ }^{1} \mathrm{e}$, especialmente, de fator reumatóide ${ }^{2}$, è causa freqüente de resultados positivos inespecificos. Pela competição de anticorpos IgG, os anticorpos IgM podem deixar de reagir nos testes, originando-se resultados negativos falsos. Para maior confiabilidade da pesquisa de anticorpos IgM, impõese associar aos testes vários procedimentos, como o bloqueio do fator reumatóide, por absorção dos soros com globulinas agregadas ${ }^{2}$, a remoção de IgG do soro pela Proteina A insolubilizada ${ }^{6}$, ou a realização dos testes com a fração IgM previamente isolada do soro ${ }^{12}$.

Com a finalidade de obter um teste mais sensivel e especifico que pudesse evitar os inconvenientes

\footnotetext{
1. Instituto de Parasitologia, Universidade Austral de Chile e Laboratório de Imunologia e Soroepidemiologia do Instituto de Medicina Tropical de São Paulo, São Paulo, Brasil.
}

2. Laboratório de Imunologia e Soroepidemiologia do Instituto de Medicina Tropical de São Paulo, São Paulo, Brasil.

Recebido para publicação em 20/11/1983. assinalados Naot e Remington ${ }^{11}$ em 1980 aplicaram à pesquisa de anticorpos IgM antitoxoplasma a técnica ELISA reversa, ou de captura de anticorpos IgM, anteriormente descrita por Duermeyer e van der Veen ${ }^{10}$, e a que denominaram técnica ELISA-IgM de duplo sanduíche (DS-IgM-ELISA). Nesses testes, fixavam anticorpos anti-IgM às placas de plástico, que captavam imunoglobulinas $M$ do soro ai incubado. A reatividade dessas IgM para o toxoplasma era pesquisada incubando-se as placas sucessivamente com um antigeno solúvel do parasita e com um conjugado antitoxoplasma marcado por enzima. Seguia-se o desenvolvimento de cor com incubação de mistura cromógena. Posteriormente, Desmonts e cols ${ }^{9}$ descreveram um procedimento que combina certas caracteristicas do teste DS-IgM-ELISA com o teste de aglutinação direta para a toxolasmose ${ }^{8}$. Nesse procedimento $o$ antígeno solúvel do parasita e o conjugado enzimático antitoxoplasma, do processo de Naot e Remington, eram substituidos por um antigeno particulado, constituído por suspensão de toxoplasmas.

No presente trabalho é apresentado um teste reverso para anticorpos IgM antitoxoplasma utilizando-se, como indicador, suspensão de hemácias formolizadas e sensibilizadas por antigenos solúveis do toxoplasma. Esta suspensão é preparada por simples diluição do reagente para o teste de hemaglutinação, anteriormente descrito por Camargo e cols ${ }^{3}$.

\section{MATERIAL E MÉTODOS}

\section{Soros}

Foram estudados 75 soros, pertencentes à soroteca do Instituto de Medicina Tropical de São Paulo. Estes soros eram mantidos a $-20^{\circ} \mathrm{C}$, conservados com 
Navarrete $N$, Camargo ME, Almeida G. Teste reverso para anticorpos IgM na toxoplasmose, com hemácias sensibilizadas por antígenos de Toxoplasma gondii. Revista da Sociedade Brasileira de Medicina Tropical 17: 13-16, Jan-Mar, 1984

igual volume de glicerina, e haviam sido submetidos a testes para anticorpos antitoxoplasma ${ }^{3}$ e outros anticorpos, dispondo-se também de informações diagnósticas diversas, conforme os casos, de natureza clínica, parasitológica ou epidemiológica. Trinta casos apresentavam história clínica e perfil sorológico de toxoplasmose recentemente adquirida do adulto, com presença de anticorpos IgM antitoxoplasma indicada pela positividade do teste IF-IgM. Os demais 45 soros não apresentavam anticorpos IgM antitoxoplasma nos testes especificos realizados e provinham de pacientes com diversas condições patológicas. $\mathrm{Ha}$ via 4 soros de pacientes com Doença de Chagas na fase aguda, com anticorpos IgM anti- $T$. cruz $i ; 8$ casos de lupus eritematoso sistêmico, com altos títulos de anticorpos antinúcleo; 8 casos de artrite reumatóide com testes positivos para fator reumatóide; 4 cases de malária, com anticorpos IgM antiplasmódio; 5 casos de sifilis recente com altos títulos de anticorpos lipóidicos e treponêmicos; 5 casos de toxoplasmose em fase evolutiva (perfil II) ${ }^{13}$, e 11 casos de pessoas clinicamente normais.

\section{Reagente de hemaglutinação}

Foi preparado como descrito ${ }^{3}$, a partir de hemácias humanas formolizadas e sensibilizadas com extrato solúvel de toxoplasma. Estes foram obtidos de exsudato peritoneal de camundongos previamente inoculados com sarcoma T.G. $180^{7}$.

\section{Teste reverso}

Para o teste foram empregadas placas plásticas em U (Interlab, São Paulo, Brasil), às quais eram adsorvidos anticorpos anti-IgM recobrindo-as com $100 \mu l$ de globulinas de carneiro anti-IgM humana diluidas em tampão carbonato $0.1 \mathrm{M}, \mathrm{pH} 9,8$, na concentração de $100 \mu \mathrm{g} / \mathrm{ml}$. As placas eram incubadas com essa solução por 18 horas e, em seguida, lavadas 3 vezes com solução salina tamponada com fosfatos $0,01 \mathrm{M}, \mathrm{pH} 7,2$, contendo Tween 20 a 0,05\% (PBST). Após nova incubação por 1 hora a $37^{\circ} \mathrm{C}$ com albumina bovina (BSA) a $1 \%$ em PBST, as placas foram lavadas novamente. Para uso, incubaram-se por 1 hora a $37^{\circ} \mathrm{C}$ com $150 \mu \mathrm{l}$ dos soros, diluídos em PBS, de 1:16 em diante na razão 4.

Depois de lavadas, as placas foram incubadas por uma noite, a $37{ }^{\circ} \mathrm{C}$, com $55 \mu \mathrm{l}$ de suspensão de hemácias humanas formolizadas e sensibilizadas com antigeno de $T$. gondii. Esta suspensão foi preparada reconstituindo-se o reagente liofilizado de hemaglutinação para a toxoplasmose e diluindo-se a $1: 8 \mathrm{em}$ PBS.

Após essa incubação procedia-se à leitura do teste, nas reações negativas formando-se um botão de hemácias sedimentadas e, nas positivas, um tapete homogèneo.

\section{RESULTADOS}

Com todos os 30 soros de casos de toxoplasmose recente $o$ teste IgM-R-HA foi positivo, sendo negativo com os demais soros estudados. Não se observaram reações negativas por competição de anticorpos $\mathrm{IgG}$, bem como reações positivas falsas pela presença de anticorpos antinúcleo, de fator reumatóide, ou de anticorpos IgM de alto titulo, decorrentes de outras infecções agudas que não a toxoplasmose.

Ao se comparar títulos dos testes de IF-IgM e de IgM-R-HA, não foram observadas divergências acentuadas, como mostra a Tabela 1.

Tabela 1 - Comparação de resultados dos testes IF-IgM e IgM-R-HA, em 75 soros humanos.

\section{IF-IgM}

\begin{tabular}{lcccccccc} 
IgM-R-HA & $<16$ & 16 & 64 & 256 & 1000 & 4000 & 8000 & 16000 \\
\hline $\begin{array}{c}\text { Não reagente } \\
16\end{array}$ & 45 & & & & & & & \\
64 & & & & 1 & & & \\
256 & & & & 2 & & & & \\
1000 & & & & 2 & 2 & & \\
4000 & & & & 7 & 2 & \\
$\geqslant 16000$ & & & & 1 & 7 & 1 \\
\end{tabular}


Navarrete $N$, Camargo ME, Almeida G. Teste reverso para anticorpos IgM na toxoplasmose, com hemácias sensibilizadas por antígenos de Toxoplasma gondii Revista da Sociedade Brasileira de Medicina Tropical 17: 13-16, Jan-Mar, 1984

\section{DISCUSSÃO}

O teste reverso para anticorpos IgM antitoxoplasma utilizando, como indicador, o reagente de hemaglutinação, mostrou-se sensivel e especifico. $\mathrm{O}$ teste é muito prático porque utiliza reagentes de fácil obtenção e dispensa o emprego de reação imunoenzimática, certamente uma limitante para laboratórios clínicos de menores recursos técnicos. Com relação à variante denominada por Desmonts e cols ${ }^{9}$ como ISAGA (Immunosorbent Agglutination Assay), a utilização de hemácias sensibilizadas como por nós preconizado torna a leitura das reações muito mais fácil e evidente, pela intensa coloração do reagente. A leitura do teste segundo Desmonts e cols apresenta a dificuldade de visualização da reação, uma vez que è incolor a suspensão de toxoplasmas utilizada como indicador. A vantagem principal do teste é a simplicidade de sua execução aliada ao fato de dispensar todo um conjunto de procedimentos relativamente complexos para fins de rotina, exigidos para remover os resultados falsos observados nos testes antiglobulinicos para anticorpos IgM, tanto de imunofluorescência como imunoenzimáticos.

Estamos certos de que o teste ora descrito poderá constituir elemento útil, no conjunto de testes para a toxoplasmose, para a definição de perfis sorológicos no diagnóstico dessa infecção.

\section{SUMMARY}

A test is described for the detection of IgM antitoxoplasma antibodies based on the technique of serum IgM capture by anti-IgM antibodies adsorbed to plastic plates. A suspension of formolized human erythrocytes, sensitized with Toxoplasma gondii antigens is then used as a indicative of anti-toxoplasma specificity of the captured antibodies. The use of sensitized red-cells instead of parasite suspensions, as previously described by Desmonts et al., 1981, results in a more practical test. Adequate red cells suspensions are easily prepared just by diluting the usual toxoplasmosis hemagglutination reagent and reading the test is much facilitated with red cells as indicator than with the colorless parasites, with clearcut results.

The test was comparable in sensitivity to the IgM-immunofluorescence test, but with no interference of rheumatoid factor or competition of $\mathrm{Ig} G$ antibodies.

Key words: Toxoplasmosis. Immunodiagnosis. IgM.

\section{REFERÊNCIAS BIBLIOGRÁFICAS}

1. Araújo FG, Barnett EV, Gentry LO, Remington JS. False positive anti-toxoplasma fluorescent antibody tests in patients with antinuclear antibodies. Applied Microbiology 22: 270-275, 1971.

2. Camargo ME, Leser PG, Rocca A. Rheumatoid factors as a cause for false positive IgM anti-toxoplasma fluorescence tests. A technique for specific results. Revista do Instituto de Medicina Tropical de São Paulo 14: 310$313,1972$.

3. Camargo ME, Leser PG, Leser WSP. Diagnostic information from serological tests in human toxoplasmosis. I. A comparative study of hemagglutination, complement fixation, IgG and IgM-immunofluorescence tests in 3.752 serum samples. Revista do Instituto de Medicina de São Paulo 18: 215-226, 1976.

4. Camargo ME, Leser PG. Diagnostic information from serological tests in human toxoplasmosis. II. Evolutive study of antibodies and serological patterns in acquired toxoplasmosis, as detected by hemagglutination, complement fixation, IgG and IgM-immunofluorescence tests. Revista do Instituto de Medicina Tropical de São Paulo 18: 227-238, 1976.

5. Camargo ME, Ferreira AW, Mineo JR, Takiguti CK, Nakahara OS. Immunoglobulin $G$ and immunoglobulin M Enzyme Linked Immunosorbent Assay and defined toxoplasmosis serological patterns. Infection and Immunity 21: 55-58, 1978.

6. Camargo ME, Leser PG, Rocca A. Detection of IgM anti-toxoplasma antibodies in acute acquired and congenital toxoplasmosis after Protein A treatment of serum. Revista do Instituto de Medicina Tropical de São Paulo 25: 201-206, 1983.

7. Couzineau P, Beaufine-Ducrocq H. Agglutination directe des toxoplasmes. Préparation de l'antigène et examen de 400 sérum. Annales de Biologie Clinique 28: 411-415, 1970.

8. Desmonts G, Remington JS. Direct agglutination test for diagnosis of toxoplasma infections. Method for increasing sensitivity and specificity. Journal of Clinical Microbiology 11: 562-568, 1980 .

9. Desmonts G, Naot J, Remington JS. Immunoglobulin M-immunosorbent agglutination assay for diagnosis of infectious diseases. Diagnosis of acute congenital and acquired toxoplasma infections. Journal of Clinical Microbiology 14: 486-491, 1981.

10. Duermeyer W, van der Veen J. Specific detection of IgM antibodies by ELISA, applied in hepatitis A. Lancet 2: 684-685, 1978. 
Navarrete N, Camargo ME, Almeida G. Teste reverso para anticorpos IgM na toxoplasmose, com hemacias sensibilizadas por antigenos de Toxoplasma gondii. Revista da Sociedade Brasileira de Medicina Tropical 17: 13-16, Jan-Mar, 1984

11. Naot J, Remington JS. An Enzyme-Linked Immunosorbent Assay for detection of IgM antibodies to Toxoplasma gondii. Use for diagnosis of acute acquired toxoplasmosis. Journal of Infectious Diseases 142: 757-766, 1980 .

12. Pyndiah N, Krech U, Price R, Wilhelm J. Simplified chromatographic separation of immunoglobulin $M$ from $G$ and its application to toxoplasma indirect immunofluorescence. Journal of Clinical Microbiology 9:170$174,1979$.
13. Remington JS, Miller MJ, Brownlee J. IgM antibodies in acute toxoplasmosis. I. Diagnostic significance in congenital cases and a method for their rapid demonstration. Pediatrics 41: 1082-1091, 1968.

14. Voller A, Bidwell DE, Bartlett A, Fleck DG, Perkins M, Oladehim B. A microplate enzyme-immunoassay for toxoplasma antibody. Journal of Clinical Pathology 29: 150-153, 1976. 